su economía hace unos tres lustros). Su capacidad actual (1967) de producción de acero supera esta cifra y promete acercarse pronto a los dos millones de torieladas. En cambio, la capacidad de absorción de la economía, ya en 1965, se acercaba a tres millones de toneladas. Resultaría pues interesante si se analizara, en cuanto a sus perspectivas, el grupo de países que se encuentran en tal situación. Nos permitimos sugerir esta tarea al Instituto de Ultramar y de manera especial al autor de este trabajo en el cual ha puesto de marifiesto tanta vocación y dominio en estos problemas de economíc mundial.

\title{
L. Saveanu
}

Horacio Juan CUCCORESE, Historia económica financiera argentina 1862-1930, Buenos Aires, El Ateneo, 1966.

El período que comprende los años 1862 a 1930 es fecundo para el historiador de nuestro país, tanto por los documentos disponibles como por tratarse de una época clave para la comprensión de la evolución histórica posterior. En esta época, la Argentina no sólo se transforma, sino que se integra a la economía mundial. Estos dos procesos, transformación e integración, íntimamente vinculados entre sí, afectan hondamente los distintos aspectos de la evolución histórica del país (demográficos, culturales, sociales, políticos, económicos). En todos los órdenes, hay cambios, agitación, revolución. La Historia económica financiera de la Argentina no podía permanecer al margen de dicho proceso. Es compleja y rica en información para comprender otros aspectos históricos del período. Y es también reflejo de las terıdencias que pugnan por imponerse, por modelar el desarrollo argentino de acuerdo a las doctrinas que las inspiran.

A esta evolución dedica el autor el presente trabajo, parte integrante del tomo de Historia Económica de la colección Historia Argentina Contemporánea, que edita la misma editorial por encargo de la Academia Nacional de la Historia, de la que el Dr. Cuccorese es miembro. Además es profesor de Historia Económica y Social en las Universidades de Buenos Aires y La Plata. 
El Dr. Cuccorese comienza el trabajo con el análisis del liberalismo económico, posición doctrinal de los hombres mós importantes del período. La aplicación de esta orientación doctrinal no estuvo a la altura de los resultados esperados. "La experiencia histórica muesira que los sanos priricipios del liberalismo económico fueron desvirtuados en la práctica. Se llegó a un liberalimo extremo que benefició a los intereses extranjeros. Se creó una estructura económica argentina parcializada, sobre bases agropecuarias. Quedó retardado el desarrollo industrial" ( $p$. 11). Según el autor, la actitud del historiador frente a los hombes responsables de esa política debe ser comprensiva, con lo cual estamos de acuerdo. "Con criterio de época - norma científica de la historia- los liberales fuerorı, en su hora, revolucionarios económicos de avanzada. Sinceramente creyeron que, cumpliendo su programa, la Argentina llegaría al pleno desarrollo" (pp. 11-12).

Pero, al analizar la generación del ochenta que impuso, "con sinceridad, el ideal librecambista" (p. 35), el autor señala las consecuencias de la vigencia de la doctrina liberal. Nos dice así: "La verdad es que el estado liberal argentirı trazó un buen programa de acción de desarrollo económico. Teóricamente perfecto, no llegó a transformarse en plan práctico de bienestar popular. Quienes recibieron beneficios directos fueron los que integraron la clase social, llamada luego oligarquía ganadera terrateniente o los aristócratas de la pampa" (p. 35). Además, "los gobernarites del ochenta pretendieron construir una Argentina como nación a la europea. Esto chocó con la realidad nacional. Entonces el régimen no pudo mantenerse en el poder, la conciencia del ser nacional irrumpió con fuerza revolucionaria. Y la generación del ochenta resultó, a la postre, la responsable directa de la tremenda crisis política, económica y financiera de 1890. Sin embargo, los cambios que se produjeron transformaron la estructura social argentina" (p. 36). El autor juzga las distintas medidas de política monetaria frente a las oscilaciones en el valor de los billetes, que afectaban diversamente a los distintos sectores. Con la creación de la Oficina de Cambio del Banco de la Provincia de Buenos Aires y la estabilización del valor del billete que se resuelve para detener la valorización del mismo, "el gobierno provincial opta por defender a la clase productora, en verdadera situación difícil, aunque transitoria, propiciando la estabilidad cambiaria. Fue una actitud socialmente injusta, pues defendía a una clase económica y perjudicaba a las demás clases sociales" (pp. 18-19). Destacamos la opinión del autor con respecto al papel del Banco Nacional y del Banco de la Provincia cuyas historias "no deben ser estudiadas aisladamente. Son partes del enfrentamiento de dos políticas diferentes, la provincial y la nacional. El Banco de la 
Provincia estaba estrechamente vinculado con los ganaderos y comerciantes, cuyos intereses giraban en tomo al comercio exterior por la ciudad-puerto de Buenos Aires. El Banco Nacional, sin desatender los negocios de los hombres de Buenos Aires, era responsable de una misión mayor, la de fomentar el desarrollo económico del interior. Y por encima de todo, imponer la unidad monetaria, el billete nacional' (p. 34).

El aspecto monetario y la creación de los institutos bancarios de que el país carecía merecen especial atención por parte del autor. Así se ocupa de las leyes monetarias básicas, de la creación de los distintos organismos e instituciones, de las vicisitudes del billete, de los problemas de las distintas emisiones y sus cor'secuencias. Las finanzas públicas, los empréstitos externos, la deuda pública tombién son tratados con el mismo rigor, así como los acontecimientos de orden político o económico que están o deben ser relaciorados con los de orden monetario y financiero para uria mejor comprensión de los mismos. Es por ello que dedica especial atención a las crisis económicas y a las dificultades financieras del gobierno nacional. Analiza la crisis económica financiera de 1873 a 1875, la de 1885, la de 1889 a 1892, la depresión como consecuencia de la primera guerra mundial, la crisis de 1920 a 1922, y firicalmente la crisis Económica mundial de 1929.

Con el advenimiento del Partido Radical al gobierno, tiene oportunidad el autor de analizar los cambios en la política oficial y los distintos y más importantes proyectos de dicha administración, donde se ponen de manifiesto las posiciones doctrinales que alentaban a los actores de los debates producidos en torno de ellos.

El trabajo es ordenado y claro, complementado por una amplia bibliografía que responde a una rigurosa selección de la historiografía económica y firianciera correspondientes al período tratado. El lector podrá sentirse un tanto desilusionado por la excesiva brevedad con que trata la mayoría de los problemas. Por supuesto, ello no va en desmedro de la seriedad del trabajo. Entendemos, sin embargo, que en ciertos casos se imponía un análisis más detallado (si bien, pareciera a veces ser intención del mismo autor dejarlo a cargo del lector). Nos referimos de manera especial a la brevedad con que analiza la crisis de 1929 y sus consecuencias para la Argentina. Ya que se incluye en el tema, hubiera sido útil tratarlo con mayor detenimiento dado que es un acontecimiento que produjo como es bien sabido, horidas repercusiones en los más variados órdenes. Esta insuficiencia resulta, sin embargo, más que compensada por los méritos del trabajo. En primer lugar una objetividad no 


\section{ESTUDIOS ECONOMICOS}

muy frecuente en los estudios sobre temas de la historia económica argentina. En segundo, la forma de situar los acontecimientos deritro del marco de las tendencias en pugna; la legislación sobre cuestiones monetarias y bancarias, presupuesto, contratación de empréstitos externos y medidas para conjurar las crisis económicas y financieras, son ubicados en su contexto histórico, e interpretadas sin perder de vista las opiniones de sectores y testigo de la época repectiva. El autor logra así dar vida a acontecimientos que en sí mismos son incapaces de expresar la variedad y riqueza de las opiniones contrapuestas que las inspiraron.

C. Picco 